\title{
BARROCO EN LA POSMODERNIDAD: LOS DESTINOS DE UN ESTILO*
}

Fernando R. de la Flor

Profesor de Literatura de la Universidad de Salamanca

El texto evoca el barroco imperial español, crepuscular, en el hoy posmoderno que el pensamiento y la vivencia de la ciudad se está despidiendo.

A Pedro Serra Definitivamente, el agitar el espectro hoy

B arroco en la posmodernidad... Los destinos del barroco imperial hispano en la actualidad... Tratar de evocar esta cuestión ante un colectivo, como el de los arquitectos y urbanistas, involucrado como agente principal en el proceso de modernización; evocar, digo, un momento retardatario, un modo productivo no enteramente sometido a la racionalización; venir a recordar (desde luego intempestivamente) aquello que está más allá de la Ilustración, donde casi nada nos es dado ver, puede resultar una pretensión anticuada, fuera enteramente de toda actualidad, inoportuna.

\footnotetext{
* El texto transcribe el fondo y a trechos la forma de la intervención oral de su autor en el contexto del Seminario de la VI Bienal de Arquitectura. Moderno-Posmoderno: un siglo. celebrado en el Palacio de la Magdalena (Santander) del 30 de julio al 3 de agosto de 2001.
} reprimido del Barroco supone, sobre todo, conjurar un momento grave de España, que nos aprestamos finalmente a enterrar en el olvido para siempre. Y con ello -y esto afecta a los colectivos mencionados arriba-, de lo que también nos despedimos es de un pensamiento y de una vivencia de la ciudad que, sobreviviendo incluso al momento moderno, ha venido definitivamente a liquidarse en nuestro hoy posmoderno.

Se trata, pues, con perseverancia impertinente de inquirir el destino de lo que sobrevive de la organización imaginaria del orden barroco en la Posmodernidad, y -dado que estamos entre arquitectos y urbanistas- ¿qué queda -si algo queda- y en qué conflicto vive - si es que vive- la potente huella dejada en el territorio peninsular por la organización conceptual del Antiguo Régimen. 
Antiguo Régimen del que puedo adelantar que, en verdad, pretendió crear en la Península un espacio donde reinara la excepción, lo que Horacio Capel ha denominado recientemente una suerte de «física sagrada», convirtiendo tal geografía, también la urbana, en una suerte de «península metafísica», y, en definitiva, en tierra entendida, prioritariamente, de manera religiosa y trascendente. Es decir: donde la disposición de lo visible sigue rangos y categorías que apuntan hacia lo invisible.

Esta deuda dejada por la era de la trascendencia, no puede ser tan rápidamente saldada ni olvidada, cuando se trata del establecimiento de una genealogía auténtica de la ciudad española, pues el proceso, como señaló Harvey en su día, es el que nos ha conducido sin duda de la «civitas christiana», a la ciudad secular, en la que definitivamente aparecemos instalados.

Ubi sunt?, como decían los elegíacos latinos lacrimógenamente, ¿qué se ha hecho de? ¿qué ha sido del Barroco y de lo barroco entre nosotros, los españoles, cuyas ciudades conocieron entonces su verdadera edad de oro, dejándose suceder después por las ciudades coloniales de la plata; por las ciudades de la cornisa norte del hierro, hasta dar en la espectaculares ciudades del titanio que porliferan en la actualidad?.

Por un lado lo que planteo es, pues, una cuestión de filosofía del patrimonio, pero por otro, el enunciado afecta a la entidad conceptual, al estatuto mismo de nuestro propio momento fracturado y definitivamente volcado hacia el futuro; lugar de quiebra y hasta de holocausto, si se quiere, de la sociedad tradicional y de sus modos de vida y de hacer ciudad.

Al preguntarse por lo moderno, este encuentro, me parece, legitima también cualquier interrogación que confronte lo que está más allá de lo moderno con lo que está más acá de él. Si este encuentro pretende, como creo, volver al problema del tiempo; conjugar el hecho de la ciudad en el modo del tiempo y, en definitiva, hacer fenomenología del tránsito entre épocas y movimientos, dejando en un lugar secundario la preocupación por el espacio y por la lógica espacial que hoy lo domina todo, entonces esta intervención mía alcanzará a tener algún sentido, ello si logra, aunque sea por un momento, traer el recuerdo de fechas que amenazan perderse en la infitud de los nuevos espacios urbanos, ya sin memoria para ellas: 1580,1609 , incluso, como veremos, $1975 \ldots$

Los problemas para abordar un objeto de esta naturaleza que busca la diacronía y que es transversal a tantos saberes, son varios. El principal de ellos relacionado con el hecho mismo de preguntarse en un momento especialmente abierto hacia su configuración de futuro, donde sólo el porvenir es determinante, por el destino o destinos que se ha reservado dentro de él a alguno de sus pasados. Pues es posible que a ese pasado no se le haya reservado en verdad ningún presente, y mucho menos un porvenir que supiera estar al menos a la altura épico-trágica de lo hasta aquí vivido.

\section{La era imperial}

Entre nosotros, el pasado por antonomasia, no puede ser otro que el de nuestra propia era 
imperial, siglo o «siglos de oro», también conocidos en teoría de los estilos como «Barroco». Núcleo, éste, fuerte del pasado pues, donde se aniquila la organización feudal y el breve sueño renacentista, y concentración de semanticidad hispana, tan fuerte y persistente, que su organización mental es capaz de enfrentarse a la Ilustración, que le sucede, ello hasta «desanimarla» y reducirla a un breve episodio, a una vigilia alucinada, más que a, propiamente, un goyesco «sueño de la razón».

Precisamente en nuestros días y envuelto en la polémica de la posmodernidad, se ha dado una primera acogida a todo ello con la obra de hace una decena de años de $\mathrm{O}$. Calabrasse, su célebre neobarroco', en la que aparecían diseñadas las estrategias formales del Barroco, de las que se aseguraba allí que informaban nuestro tiempo, nutrían las operaciones típicas de la posmodernidad.

Habría, pues, una operatividad formal barroca, bajo cuyas leyes, además -y ahí estaría el interés de su retombe, de su vuelta-, se situaría gran parte de la producción simbólica actual. Desde luego, por ejemplo, bajo su esquema productivo se ubicaría toda el área del espectáculo de masas, al que propia y justamente podríamos denominar en gran medida «barroco»; pero también los procesos sociales de comunicación -como el cartelismo, la publicidad, la inundación de la ciudad colonizada por la letra...-. Todo esto tiene exacta una genealogía en las técnicas de poder desarrolladas con suma efectividad por el absolutismo confesional que controla virtualmente -desde 1580 , pero intensificado en 1609, con la expulsión morisca-, la urbe his- pana, antiguamente mestiza, arabizada, ingobernable, reduciendo su entropía, su desorden, y homogeneizando a las masas con técnicas que han sobrevivido y se han perfeccionado.

Calabresse tendría hoy para nosotros el mérito -y de ahí la acogida privilegiada dispensada a su libro- de haber individualizado los procesos retóricos que gobiernan la gran producción barroca, y de haber, además, señalado su persistencia y sofisticación en nuestro momento posmoderno, contribuyendo así a afirmar la presencia de aquel pasado en este presente.

Así la sustitución, la proliferación, la condensación terminan constituyendo la poética escueta que nos gobierna, y en ella debemos reconocer la herencia formal, no de ningún momento ilustrado, sino precisamente, la conexión privilegiada con ese momento bizarro, arriesgado, y hasta entrópico y letal, que significó el conceptismo y el culteranismo barroco, del cual vendrían directamente la organización general de los efectos retóricos de nuestro tiempo. La vuelta a la retórica actual, es la forma técnica de la vuelta del Barroco, que insidiosamente se propone a nuestro presente como gran máquina y fábrica potente del imaginario artístico.

Ideologías de la forma que hoy sabemos no quedan reducidas al dominio de la lengua literaria, sino que, en realdiad, permean todo el campo de producción social, ya sean cuadros, modos de concebir planteamientos de una batallla o, propiamente edificios, dando así entre nosotros: pintores conceptistas, urbanistas culteranos y arquitectos jerigoncistas, 
incluso, ambidextros de las dos escuelas, como entre todos resaltan esos Churriguera, a los que la poética clasicista denomina «bárbaros» y bizarros en el idioma de la arquitectura, y cuyo nombre de escuela no estaría de más todavía aplicar a los arquitectos de los excesos manieristas y dilapidadores que caracterizan la década de los ochenta/noventa.

En otro orden de cosas, podemos asegurar también que la persistencia o huella mnémica del barroco o de lo barroco entre nosotros estaba vinculada también, no sólo a un mero problema de estrategias formales y de modos operacionales, sino a unas ideologías trágicas y a un pensamiento hispano de lo fatal, que sitúa el proceso histórico siempre a un paso de la catástrofe y de la desrealización del mundo.

El «desengaño» hispano barroco desemboca directamente al cabo de los siglos con la experiencia contemporánea de vivir la posutopía. De cabo a rabo, el mismo modo de vivir el malestar en la cultura, la continua disolución y crisis de los valores sociales que tiene como escenario la ciudad.

La vida es sueño, podían decir en este sentido los barrocos, y saltando por encima del momento de diafanía iluminista que representa la Ilustración, y a la vista, por ejemplo, de las grandes cosmópolis y conurbaciones, nosotros también podemos decir con Calderón que, en efecto, la «vida nos parece un sueño».

La obra de Severo Sarduy, entre los años sesenta y setenta -años clave para la suerte de la teoría posmoderna-, trató de vincular activamente el espíritu de época a una retombée o «eco» de las grandes vectores que habrían presidido el momento barroco, hermanándonos con él. Nuestra producción simbólica, poseída por un «viento barroco» aun «sin norte» (como escribía a principios de siglo D’Ors y recuerda hoy Jarauta), estaría en efecto movida por el impulso alegórico que determina hoy toda realización, y que consituye, según Benjamin, la ley estilística dominante en la era barroca, igual que en la posmoderna.

La estética, en efecto, y más precisamente los iconos más significados de la arquitectura nueva, como aquella barroca, aparece hoy presidida en profundidad por un efecto acusado de trompe l'oeil, de simulación, de engaño y de fantasmagoría, donde también opera la argucia, la disimulación, sobre todo, pero también, el travestismo, y camouflage, la transmigración, el mestizaje discursivo, y, en general, todas las estrategias que tienden finalmente a la desmaterialización, y mediante las cuales «los objetos, el mundo, el universo referencial se ve espectralizado».

Es también en ese sentido que podemos pensar que la arquitectura posmoderna y el urbanismo responden a este espíritu complejo de lo barroco; algo que busca desesperadamente volcarse en la construcción de un campo de acontecimientos progresivamente más complejo bajo el régimen generalizado de Proteo y de la transformación, mientras se ve sometido a un vértigo de interpenetraciones que lo convierte en un territorio sin imagen estable, sin código interpretativo maestro, dando así 
testimonio del funeral por la significación y el referente perdidos en este otro fin de siglo.

Mucho más que el simpático perrito floral del Guggenheim, es la poderosa Circe, por un lado, y, sobre todo, el asombroso pavo real, por otro, como en el gran libro de Rousset, que describía los fenómenos cortesanos barro$\cos$, los que siguen siendo los emblemas verdaderos de un momento proceloso, donde se ha puesto en pie la duda sobre propia entidad real de lo real mismo.

Sólo que esta duda razonable ya no formaría parte de un desgarro metafísico, sino que, como ha escrito Sánchez Robayna, el barroco, en esto, vuelve a nosotros como barroco light, barroco «de la levedad», un neobarroco que habría perdido en sus realizaciones mayores la gravedad finalista y atormentada que presidió su primer momento, en tanto estilo o «modelo de la profundidad».

Las grandes cuestiones dramáticas se han vuelto súbitamente irrelevantes, en consecuencia también los grandes modelos de ciudad trágica española (y hubo un tiempo en que casi todas lo eran, de Llerena a Toro, de Trujillo a Ciudad Rodrigo o Morella) se desmantelan en nuestros días para convertirse rápidamente en parques temáticos de la españolidad esencial.

\section{Spain was different}

$\mathrm{Y}$, sin embargo, incluso pese al título y la promesa implícita en él, no desearía entrar en ninguno de estos modos del retorno barroco (el del drama y el de la retórica) a nuestro tiempo, que, por lo demás ha tenido entre nosotros destacados analistas, como pueden serlo Subirats, Brea o Jarauta.

Más bien quisiera cambiar el sentido de la reflexión y retomar una dimensión local del problema, quiero decir con local, penínsular, española si quieren, cosa esta última que no es la habitual ya entre nosotros (como un efecto más, yo creo que indeseable, de la globalización y la mundialización de nuestros referentes).

Entonces quisiera dedicar algun espacio al hecho mismo de preguntarme si la sociedad española ha superado definitivamente su imaginario imperial y barroco, y, de haberlo hecho, cuándo lo ha hecho, e, incidentalmente también, como ello influye en el paisaje de los acontecimientos y termina conformando también el territorio de nuestro tiempo.

Me pregunto por la suerte de nuestro capital barroco (e incidentalmente me preguntaré también por el destino que han recibido las capitales barrocas y, en general, los grandes hitos y referencias barrrocas, que me parece emprenden ya sin paliativos el camino final de un destino en la industria del ocio, como ese palacio ducal de Lerma, expurgado de su aura poderosa y presto ya para servir al país en la forma de uno de los mejores paradores de Europa).

$\mathrm{Y}$ ello porque pienso que, como un efecto también perverso de la propia dinámica de la transición y el potente desarrollo económico que la ha seguido, hemos sido lanzados hacia el futuro, lo que equivale a decir también, que 
hemos sido bruscamente desterritorializados y desubicados de los primitivos marcos de referencia.

En el trayecto algo importante se ha perdido, empero. Los sicoanalistas dirían que los duelos pertinentes por el padre y el pasado enterrado no se han celebrado adecuadamente; es posible, entonces que los espectros nos visiten para recordarnos las deudas para con ellos. Probablemente quieren sentirse parte de ese futuro que nosotros nos disponemos a abrazar, como si hubieramos nacido sin simiente ni generación de otros. Hijos en realidad de nada y productos, más que de una transición, de un proceso intencional de olvido, de, como diría Jameson, una exclusión estructural de la memoria.

Un poco desterritorializados y desubicados. En efecto, la prueba es esta obsesiva reflexión que hoy se vuelca íntegramente sobre la topología del porvenir, sobre el espacio del futuro. Nos obsesiona el paisaje del mañana, cuando recién hemos abandonado la casa de tierra del ayer, mientras todavía por doquier pueden encontrarse las ruinas de un orden recién abandonado en proceso ahora de rehabilitación (como se dice).

No bien se cierra, en los años 74 y 75 , nuestro sueño colonial e imperial, común con los portugueses, y abandonamos los territorios africanos -Angola, el Sáhara, Guinea...- el país ha sido obligado en todos los terrenos a dejar atrás para siempre las formas expresivas de su marginalidad fantasmal y el cómodo hábitat de lo periférico; ello para abrazar el centro duro de la vanguardia del proceso transformador, como noveno miembro in pectore del G-8.
Lo cual se deja sentir, sobre todo, en nuestras ciudades, realmente metidas en un proceso reformulador, que es acaso lo más significativo y relevante de lo acaecido en el decenio transcurrido entre 1990 y 2000.

Han sido en total apenas veinticinco años dedicados minuciosamente a olvidar el pasado, con el objeto de reubicarse en el centro de una totalidad de escala planetaria, y éstos no parecen ya tantos, sobre todo cuando se piensa de qué materia prima está de verdad hecho este país, y surgiendo muchas dudas acerca de si anímicamente también ha podido producirse este cambio en una sociedad que hace tan sólo sesenta estaba ampliamente ruralizada, y sometida todavía al principio de unas ideologías forjadas en la era de los felipes (de los que el franquismo, como se sabe, se soñaba sucesor y heredero).

Así que, propiamente, la velocidad de cambio ha determinado el que no se trate ya de efectuar una mera superación del pasado, sino que ha sido en verdad necesario todo un proceso de encriptación de la experiencia histórica, acompañado de una reescritura de la historia, un lavado de su cara, conectado con la Reforma y con el papel desempeñado en ella por grandes historiadores, entre los que destacaremos a nuestros efectos a Maravall padre, un maestro, como también lo fue el hijo (ministro de Educación), en dar un giro al pasado para hacerle confluir armónicamente en la marcha ineluctable de la historia, haciendo que de una vez el pasado de verdad pasase.

1975, la fecha del libro de Maravall - La cultura del Barroco- nos da en efecto la pista 
documental de sobre cuándo se dejó de vivir en España bajo el orden imaginario del Antiguo Régimen y, definitivamente, se pasó a esa tercera fase del capitalismo, de su régimen de bienes simbólicos y, en general, de su nuevo imaginario.

Se trataba entonces de saber en qué punto preciso de estos años que corren desde una modernidad (prácticamente inexistente) a la posmodernidad (a la sazón totalmente triunfante) se ha producido la gran cesura, el corte, o la quiebra misma de la tradición autóctona, y cuándo es que nos hemos despedido de nuestro pasado, renunciando a él, así como bajo qué estrategias, éste ha podido desaparecer virtualmente bajo nuestros ojos o, como veremos, alcanzar a invertir enteramente su sentido.

Puede parecer un escándalo, pero, en efecto, todo se encamina a confirmar que el país se mantuvo en lo sustancial atado a un orden imaginario y simbólico enteramente dependiente de su primera fase imperial hasta el año de gracia de 1975. Los momentos liberales, ilustrados, los años de avance y progreso franco hacia una sociedad emancipada en ese largo sueño acunado por la autarquía, el providencialismo y la xenofobia del absolutismo confesional, han sido, breves, episódicos y, cuando se han producido, lo han hecho, como analizó Subirats en su día, a propósito de una debilísima ilustración española, en tanto siempre que insuficientes.

El episodio culminador y monstruoso en sí mismo del franquismo así, aun a pesar de someterse a renovadas operaciones de liffting, que remodelan el cuerpo anfibio de la nación, resulta ser sustancialmente, bajo esta mirada, sólo la prolongación de la vida agónica de ese antiguo régimen en la vieja piel de toro.

Francisco de la Rubia ha señalado de manera brillante en su Franco como ciborg como el propio cuerpo monotorizado, cuasi cibernético, del caudillo terminal se convierte en la metáfora perfecta de la hibridez entre la nueva matriz tecnológica y la vieja raíz telúrica de lo carpetovetónico.

Pues si bien ese cuerpo agónico del Caudillo recibe las prótesis de la última tecnología biológica, es verdad también que, por encima de los instrumentos que prolongan sus últimos momentos de vida, se tiende, pudoroso y rutilante, el mantón milagrero de la Virgen del Pilar; Viéndose auxiliadas las operaciones de la cirugía de precisión por la intervención salvífica de la mano incorrupta de santa Teresa que siempre favoreció al $d u x$ hispano.

Lo que, a todas luces, no hace sino conectar el espacio de la clínica donde agonizó el franquismo en el noviembre invernal del 75 con ese otro lugar taumatúrgico, lugar de declinaje de los Austrias, que fueron El Escorial o el alcázar mạdrileño, donde los cuerpos reales -el de Felipe II y el de Carlos II, especialmente- de modo literal se pudrían, retrasando así el momento de las inevitables crisis por venir y las correspondientes cesuras e hiatos dolorosos que las muertes de los taumaturgos siempre han de causar en las sociedades como la nuestra, arcaicamente organizadas.

Una frontera, un borde y un borne temporal pasa así por aquel cuerpo agónico del año 75 , 
definiendo, hacia delante el vertiginoso proceso de cambio español en la posmodernidad, y situando, al otro lado de lo definitivamente olvidado las sombras del pasado.

En ese cuerpo singular y simbólico en el que encarnó el Padre y el Estadista, se vienen ciertamente a unir y luego a separar definitivamente la retórica del nacional-catolicismo, de un lado, y, de otro, las realidades tecnocráticas que no tardarían en ser determinantes y exclusivas para el país, llevando todo hacia las aguas del mercado.

De hecho, entonces, el paisaje cívico sobre el que proyecta su imagen el Generalísimo, en sus cuarenta largos años de vida política, no es otro que el mismo viejo y sempiterno paisaje ascético, en el fondo del cual siempre se cons- con grandes consecuencias para el paisaje edificativo de nuestro país y para sus políticas de conservación patrimonial, los últimos actos de ese drama de los tiempos en que consiste precisamente la demostrada renuencia del país a entroncar con un modelo o vector fuerte de progreso, y a adoptar $-y$ hasta abrazar francamente- lo que en términos de Weber llamamos la «ética del capitalismo».

El abrazo del oso de ese movimiento hacia el desarrollismo que se inicia en el 64 y culminará en el 75, supondrá también la desaparición de la diferencia cultural y el final programado de un modelo propio de ciudad española, para lo que a historiadores de la arquitectura y el urbanismo español les interesa.

Y decimos que eso se produce en 1975, porque todo parece indicar que no fue hasta entonces que una transformación de esta naturaleza pudo suceder. Aunque eventualmente, entre tanto, como veremos, ciertos gestos modernos $-\mathrm{y}$, si pensamos en Benidorm, como ejemplo, en realidad, ultramodernosse habrían comenzado a producir mucho antes de esa fecha.

\section{La península pentagonal}

Pero el tránsito de la organicidad de Franco, el pasaje de su corporalidad orgánica a su nueva dependencia de máquinas y prótesis exteriores, hacia las cuales se realizó en verdad un transfer de su espíritu en los últimos días y meses del 75, metaforiza, en tanto cuerpo expiatorio y transferencial, el cambio de piel y de identidad del país, y nos sirve 
como una auténtica «puerta del tiempo»², especialmente a quienes, no siendo sociológos ni economistas, y no compartiendo sus discursos rigurosos, vivimos en realidad de las construcciones imaginarias y mitopoéticas, dentro de un régimen de alegoría continuada en el que confiamos nos debe servir para explicar nuestro mundo al menos.

En fin es una propuesta: toda cuestación de la modernidad o la posmodernidad pasa forzosamente sobre esa fecha liminar, a través de la cual estamos llamados nosotros a organizar la experiencia histórica, y naturalmente a través de la cual también debemos dar cierta cuenta del devenir de la ciudad española.

Como ejemplo de esa pervivencia del Antiguo Régimen, respecto al cual el franquismo no es sino su suplemento y coda final, cabe decir cuando se examinan momentos estelares inmediatamente anteriores, que, por ejemplo, todavía en 1920, en el momento en que Mario Praz visita la Península, la encuentra dormida en su sueño de siglos, francamente incorrupta. Cuando esa vitrificación (grata a los conservadores) es detectada -por este dandy del conocimiento- lo es en calidad de auténtica excepción y anomalía, tanta que, incluso, rechazará el primer calificativo que le da al país para su libro -«España pintoresca»-, y abandonando para siempre la senda de los románticos, fustiga al país francamente atrasado, bautizándolo, de modo genial, como $L a$ peninsula pentagonal, queriendo resumir en esa figura de cerramiento del orden geométrico, cuanto en ella se circunscribía de pasatismo en torno a las huellas de un viejo orden fósil.
Cuando por aquellos mismos años Buñuel emprende el proceso de su primera película política, Las Hurdes, encuentra por maravilla que los restos de la vieja sociedad rural austria perviven en España, en un territorio donde la condición no-progresada todavía se vive en realidad como delirio y pesadilla.

En esas fechas, y para la mirada del protomoderno Buñuel, todavía no han cambiado las profundas geografías hispanas, cosa que demuestra emblemáticamente el cineasta refiriendo cada uno de los gestos de aquellos sus actuales hurdanos a la teratología artística de enanos, monstruos, bufones y mujeres barbudas, en donde la pintura española del Siglo de Oro consigue testimoniar una visión del mundo turbulenta y ya para siempre dramática.

España estaba aquí dada como diferente, y esa diferencia era teatralizada, dramatizada por el cineasta. Ni un atisbo, ni un asomo siquiera de modernidad, de tiempos nuevos, había llegado entonces, a la altura de los treinta, a ese hábitat monstruosamente retardatario de 10 hurdano, que en cierto modo se convirtió, por la fuerza del discurso mitopoético que Buñuel sobre él traza, en un emblema, y más bien en un jeroglífico, del modo hispano de habitar la tierra.

Antes, en los años diez o doce, Azorín había podido exhibir también con la filigrana de su estilo y en los primores de lo vulgar hispano una descripción cumplida del ambiente tridentino en que se desenvolvían las capitales españolas en los días grandes de las festividades eclesiásticas. Rindiéndose, como por entonces lo hacían los máximos escritores del 
país, de Clarín a Miró, de Palacio Valdés a Baroja, ante la experiencia pura de una civitas christiana, mantenida todavía contra todo pronóstico en los tiempos de la muerte de Dios y de la secularización de la ciudad.

La reflexión que hace Azorín, otro «moderno», sobre por qué el pueblo español es el único pueblo de su contorno que todavía levantaba catedrales a principios de los años veinte, merece estudiarse como un análisis acerca de lo retardatario y la persistencia de huellas mnémicas en una actividad, la arquitectura, de la que se dice que sólo puede progresar, nunca detenerse, jamás volver atrás.

Muchos entusiastas ideólogos de aquel entonces sancionaban el caracter anticuario e insobornable de las capitales espirituales españolas. Unamuno trazaba por aquellos años de los principios genéticos de la modernidad la etopeya de la civitas católica, y exprimía en textos de todo género los sentidos que esta ciudad retardataria y metafisica exhibía en contra de las capitales del progreso y el cambio.

En otros lugares he hablado de ello, y no quisiera deternerme ahora en este significativo autor de la metafísica de la ciudad, próxima a la que en aquellos años construye también De Chirico.

Pero cabe decir de todo ello, que ahí se alcanzó un punto de imposible superación en la elaboración de un discurso mitológico sobre el ser de la ciudad. Ni el mejor Almódovar, en la mejor de las secuencias sobre Madrid, ha logrado superar al maestro de la somatización, a ese Unamuno, experto fundidor de pasados y vivencias en el crisol de las imágenes poéticas citadinas. Ello hace buena la observación de Jameson, en cuanto que lo que ha podido ocurrir es que recluido en el ámbito de la nostalgia pasatista y del espiritualismo, suponemos que el modelo descriptivo unamuniano ha muerto, sin en realidad haber sido sustituido por nada. Como nada, en efecto, es posible de concluir ante los paisajes de la ultramodernidad, dado que, como dice el teórico:

Esa extraña superficie nueva que se extiende ahora convierte rotundamente nuestros antiguos sistemas de percepción de la ciudad en sistemas arcaicos y sin objeto y sin ofrecer otros a cambio.

\section{Barroco ¿eterno?}

En efecto, la cosa es grave, se ha podido producir entretanto la temida ruptura de la intimidad entre cuerpo y entorno edificado, un desarraigo que las arquitecturas de esta hora no son con todo capaces ya de suturar. En todo caso, son los discursos los que ya no pueden cartografiar ni ubicarse dentro de la totalidad urbana, porque el espacio ha dejado de ser mensurable y reconocible.

Digamos que el lugar se ha disuelto en una abstracción mayor, y ya no existe, al menos con el significado que le dieran los latinos: locus. En cuanto al tiempo mismo, éste ha perdido, en las representaciones que de él nos hacemos, la densidad que antaño tuvo, en los tiempos de Proust y de Bergson, o en los de nuestros proust y bergson, digamos Machado y Azorín, Zuloaga y Miró. 
Después de estos hombres y estos nombres, podría decirse que la ciudad, definitivamente, ha perdido su poesía, y poco a poco frente a a las grandes conurbaciones ha desaparecido el espíritu de penetración, de «detournement», de travesía y encuentro poético que estuvo vivo hace tan sólo tres decenios, y que de modo tan preciso analizara Debord, el último de entre nosotros que parece supo en qué consistía la ciudad, y qué hacer con ella: naturalmente ponerla en estado de excepción, provocar en ella el cortocircuito de su aberrante racionalidad, levantando su piel, su asfalto y macadam, para encontrar debajo de ella lo Real perdido: de nuevo, el tiempo, de nuevo, el juego de la finitud y de la permanencia.

En sintonía con ello, en aquella otra hora, entonces, los ideólogos de lo hispano soñaron con la inmanencia de un tiempo que se quería eterno: un barroco eterno que se les hacía presente en sus biografías:

«Era en Numancia al tiempo en que declina la tarde del agosto augusto y lento», podía escribir por entonces Gerardo Diego.

Entonces se podían apreciar los misterios de la «dureé» y la memoria. Aquellos otros hombres valoraban y percibían el tiempo, proustianos ellos, mientras nosotros percibimos y valoramos la espacialidad, la superposición infinita de superficies.

La densidad de la memoria edificada era tanta y estaba por entonces tan residenciada, que el sentimiento mismo de su visualidad engendraba entonces la vivencia; ese término heideggeriano que sirve para expresar la cons- trucción simbólica del objeto de arte y de reflexión. Y que ha encontrado en el siglo su hábitat en dos lugares precisos sólo: los campos de batalla y las ciudades con resonancias históricas: Verdún y Belchite, pero, también Venecia y Sepúlveda.

Del elogio y la exultación por la presencia incólume del pasado, se podía fácilmente pasar a desear la perpetuación e inmanencia histórica de ese pasado no afectado por el progreso, reclamando entonces, no «cirujanos de hierro», sino, en realidad, «anestesistas de acero» y cerrajeros para convertir en una caja de seguridad el sepulcro del Cid.

Suponía ello aceptar -y esto en un país con sentimientos de decadencia es explicable-, que el pasado debía convertirse en una suerte de definitivo presente y hasta en un futuro.

Entonces, en el largo tiempo en que esta inmanencia y detenimiento del tiempo se vivió, pudo escribirse ese libro singular a todos lo efectos, por un autor que ha pasado por ser uno de los más representativos del momento. En efecto, Elogio, pero también nostalgia: Elogio y nostalgia de Toledo. La vista de estos intelectuales carpetóvetónicos en que se mostró pródiga la Península, se extasiaba complacida por entonces, no hace después de todo demasiados años, ante el perfil bajo de las ciudades españolas de la Contrarreforma; se extasiaba efectivamente en el sueño de pervivencia de un estilo -el barochus Hispanus, como lo llamó D’Ors-, que no moriría nunca, sino que, al contrario, podía asegurarse de él que un día todo el mundo se rendiría a la diferencia hispana, y llegaría a 
renocer en nuestra tierra la bendición de la existencia de un paradigma desviado pero insobornable de la cultura occidental.

Ocurrió entonces que ese D'Ors saludando a los Churriguera y sus arquitectura visionarias, escribiera oracularmente:

Churriguera arquitecto maldito, sirena deliciosa... Tus altares en las iglesias hispanas, tus portales madrileños, tu salmantina casa municipal, me traen y traerán un día al mundo, con el desbordamiento tumultuoso de la pasión, con todo su mal gusto, un trágico cantar de abismo y de océanos...Preveo para Churriguera, en hora próxima, una justiciera venganza.

El crítico, en su singular idiolecto castellano, podía haber dicho: «mañana, en nuestro país, [seguirá haciendo] hará Barroco».

Pero pudo ser también Tovar, Giménez Caballero, Sánchez Mazas, o, significativamente, también Ortega los que teorizaran este momento barroco imperial y al mismo tiempo supuestamente eterno ya de las cosas de España, los filólogos y los teóricos de la literatura y la historia, al modo menenedezpidaliano apoyaban esta presencia fuerte de la tradición y exaltaban el pasado, en tanto el porvenir empezaba a llegar insidiosamente, desde donde siempre ha venido el sol y el futuro: de la fachada del levante peninsular

Ese paisaje espiritual arcaico ciertamente no había cambiado todavía por los años sesenta en que se inicia en la periferia española los procesos verdaderos de remodelación física del territorio. Quiero decir que extrañamente pudieron convivir Benidorm de un extremo y las episcópolis castellanas de otro. Pero, entretanto, la operación de wripping, como denomina Jameson a este efecto de «encapsulamiento» y de opa hostil que el presente lanza sobre el pasado, estaba ciertamente en marcha.

Ajenos a su destino ocluido, los discursos mitopoéticos todavía soñaban una España duradera, singular, eterna. Todavía en esos años El Escorial es el edificio representativo de España; clave suprema del país, tanto que Luis Martín Santos, como antaño Ortega, le dedica una meditación, Meditación del Escorial, ahora en su Tiempo de Silencio. Meditación a la que los arquitectos novísimos también de nuestros días, vuelven siempre como a unos ejercicios espirituales, tratando de recargar las pilas de la kriptonita cultural en un momento, como éste, al cabo desvitalizado. Meditación, en cuya conclusión se puede decir aquello que dijo Baudelaire: $« \mathrm{O} \mathrm{Oh}$ ese monstruoso estilo jesuítico que me agrada tanto!».

Basilio Martín Patino pudo realizar también por aquellos años su captación maestra de una Salamanca, capital bélica del fascismo (treinta años después del 37 se diría que el Cuartel general de Franco recién había sido levantado), y que, saltando todavía más allá de los años, ofrecía todavía al espectador en sus ruinas el esqueleto mismo de la ciudad que fue hasta finales precisamente del período barroco.

En la película una escena refleja la vuelta de un exiliado de la guerra que encuentra todavía maravillado de qué modo en lo esencial, la 
ciudad no ha cambiado de cuando la abandonó en el año 36. El discípulo de Unamuno encuentra sorprendido como en el seno de un mundo en transformación rápida, el caserío y hasta el espíritu de la Salamanca eterna se mantiene, al modo, dice él, de una cápsula o burbuja temporal. Se trata del efecto embalsamamiento de toda una sociedad, y cuando de una reflexión como ésta se trata, acerca de la ciudad moderna y posmoderna, no puede olvidarse este hecho que nos singulariza (o estigamtiza, según prefiramos) para siempre.

En España, al menos por entonces, ciertamente, no pasaba lo que en París donde según la célebre expresión baudeleriana, incluso en el XIX la ciudad ya lograba cambiar más rápidamente que los estados del espíritu de quienes la contemplaban.

Pero entre esta obra y nuestro presente, se debe ahora sitúar en efecto, en algún lugar, esa cesura que nos hemos prometido localizar, pues cuando ya en nuestros días un Álex de la Iglesia debe colocar en algún punto de los mapas la venida de un nuevo Anticristo, aunque todavía tiene que recurrir tipológicamente a fantasmas del pasado barroco, como son esos curas de la Compañía de Jesús, no tiene más remedio que situar el nacimiento en ese nuevo e inverso «portal de Belén» que forman las torres de Kio sobre la Castellana.

Madrid, de «capital ceremonial del imperio» barroco, pasaba así a nueva capital diabólica del mundo, invertida urbs imperial, pues fue precisamente la inversión financiera de capital árabe de los años ochenta y noventa, la que acomete un acto de venganza lírica, reme- dando a la distancia de los siglos una nueva invasión de la Península (seguida es verdad, esta vez de una rápida reconquista cristiana, si miramos el destino seguido por el señor de la Rosa).

El juego de raports y guiños entre nuestra antiguedad imperial y el presente no se detiene ahí, pues, en propiedad, tan sólo podemos buscar la Historia mayúscula a base de simulacros, ironías, inversiones especulares.

Hay una ironía explícita en el hecho de que un fenómeno, asociado a la atracción que ejercen las urbes modernas de españolas sobre el imaginario del Tercer Mundo, cual es el de la inmigración legal o ilegal, que abre vectores de acceso desde sociedades rurales o ruralizadas a grandes conurbaciones, invierte hoy paródicamente en nuestros días, lo que significó el cierre de otrora de las ciudades españolas a la alteridad y al mestizaje.

En efecto, un trayecto aquí se ha invertido siendo sus consecuencias igualmente dramáticas, pues si hoy los inmigrantes de las pateras son capturados a lazo en las carreteras y caminos que conducen a las ciudades españolas, hace quinientos años fueron estas mismas ciudades las que expulsaron a estos hombres de sus muros. Así que al menos en este aspecto, podemos decir de ellas que siguen inmovilizadas en una suerte de gesto despótico de signo barroco, absolutista, excluyente para con lo diverso y, al fin, dogmático.

Y es que cuando hoy admiramos las bellezas escleróticas y finalmente desvitalizadas a fuerza de intervenciones de los grandes restos 
y supervivencias arquitectónicas de la era imperial, no se percibe enteramente de qué suerte de historia y cargas trágicas están constituidas éstas que son hoy puramente destinos (recordemos: «los destinos del Barroco» para una estetización difusa de las masas.

He aquí el corpus delicti, el núcleo escamoteado de lo barroco, lo encriptado y no reconocido nunca de nuestra historia nacional.

El hecho mismo es que todo documento de cultura, como dice Benjamin, lo sea, al unísono, también de barbarie.

Pues conviene saber sobre lo que fueron los procesos de formación de la ciudad barroca que tanto admiramos, convertida hoy en parque temático de sí misma, allá donde haya logrado trabajosamente subsistir, el que ésta funda su existencia en procesos de exclusión y en efectos de sujección de masas, y esta percepción de la profunda incorrección política y moral del pasado hispánico, es el que determina todo el movimiento final hacia su extinción entre nosotros, y el hecho mismo de que nadie derrame lágrimas por este final de régimen para la aventura de la singularidad hispana.

Terminemos con una parábola profética, en verdad no cumplida, pero que gravita hoy como ayer sobre cualquier destino de la ciudad moderna, modernista o posmoderna; barrroca o virtual y telemática.

En los inicios del proceso de decadencia española, se produce un escrito anónimo importante que ha llamado recientemente la atención de los historiadores se trata de una profecía, de un sueño milenarista, contenido en el llamado «El sueño de la ciudad en ruinas».

El autor ha visto la ciudad hispánica y la ha reputado como insolidaria, atroz, babélica, dominada por los fuertes, entregada a los espectáculos inmovilizadores, en poder de los mistagogos. Entonces escribe su anatema de ella. Es un texto que a través del tiempo nos llega aún, y nos alcanza todavía, aunque haya perdido su mordiente profético y su amenaza savonarolista se haya disuelto en el aire.

Va dirigido a las ciudades que, como las españolas, se han convertido en bastiones y ciudadelas, en plazas fuertes en realidad y zonas de seguridad reforzada, donde se defiende un orden injusto y un régimen de engaño generalizado.

Entonces el autor escribe:

Sea glorificado en la ciudad aquel que tiene cuidado de los pobrecitos, levantando a los que están durmiendo en el rescoldo de la ceniza, entre los perros y los gatos, y en los escondrijos asquerosos de la ciudad, para que, justamente, éstos posean el lugar de los hinchados y soberbios que duermen en las regaladas y ponzoñosas camas y debajo de los soberbios edificios edificados con sangre de miserables.

\section{Breve referencia bibiliográfica}

El concepto de una «física sagrada» ha sido enunciado por $\mathrm{H}$. Capel, en su estudio $L a$ física sagrada. Creencias religiosas y teorías científicas en los orígenes de la geomorfología española (Barcelona, Ediciones del Serbal, 1985). El de «ciudad secular», que alguna vez emerge mencionado en mi texto, ha sido 
acuñado en la lectura atenta de la obra de título homólogo de H. Cox (Barcelona, Península, 1983).

Cuando aquí se evoca el problema del tiempo y lo que es la «lectura del pasado», entonces se entra en territorios definidos en su día por P. Ricoeur, en su La lectura del tiempo pasado. memoria y olvido (Madrid, Arrecife, 1999), aunque a este respecto no se puede tampoco olvidar el gran libro de R. Assunto, El pasado en el presente (Barcelona, Gustavo Gili, 1979).

Los problemas formales de un neobarroco, han sido tratados fundamentalmente por O. Calabresse en su La era neobarroca. Madrid, Cátedra, mientras que la conexión barroco/posmodernidad ha encontrado su últimno analista en I. Chiampi, Barroco y modernidad. (México, Fondo de Cultura Económica, 2001) la obra inaugural de Sarduy es, naturalmente, la de Barroco, publicada en Editorial Sudamericana en 1974. Digamos de la modernización de «lo barroco», que tiene dos padres fundadores, El D'Ors que por los años treinta publica su Barroco, y el Benjamin que también publica por esa época su célebre El origen del drama barrroco alemán (con edición española en Madrid, Taurus, 1990).

Las alusiones al «franquismo cibernético» proceden del artículo de F. de la Rubia, «Franco como cyborg» (Ciberkiosk, pt)

Me he acercado a un concepto de «barroco hispano» en mis libros La península metafísica. Arte, Literatura y pensamiento en la España de la Contrarreforma (Madrid, Biblioteca Nueva, 1999) y en mi Barroco. Representación e ideología en el mundo hispánico (1580-1680) (Madrid, Cátedra, en prensa). Por último, para una visión de los problemas específicos que plantea el concepto de ciudad histórica española, véase mi: «La ciudad histórica y el pensamiento español», en Baurg 00, Revista de los Colegios de Arquitectos de Cantabria y Castilla y León, 1 (2000), págs. 2-9.

\section{NOTAS}

\footnotetext{
' Maria Zambrano ha reflexionado sobre este tipo de muerte fragmentada, ritual y simbólica en la que incurre el Dictador, ello en su «la muerte apócrifa», en M.
}

Gómez Blesa (ed.), las palabras del regreso. Salamanca, Amaru, 1995. 


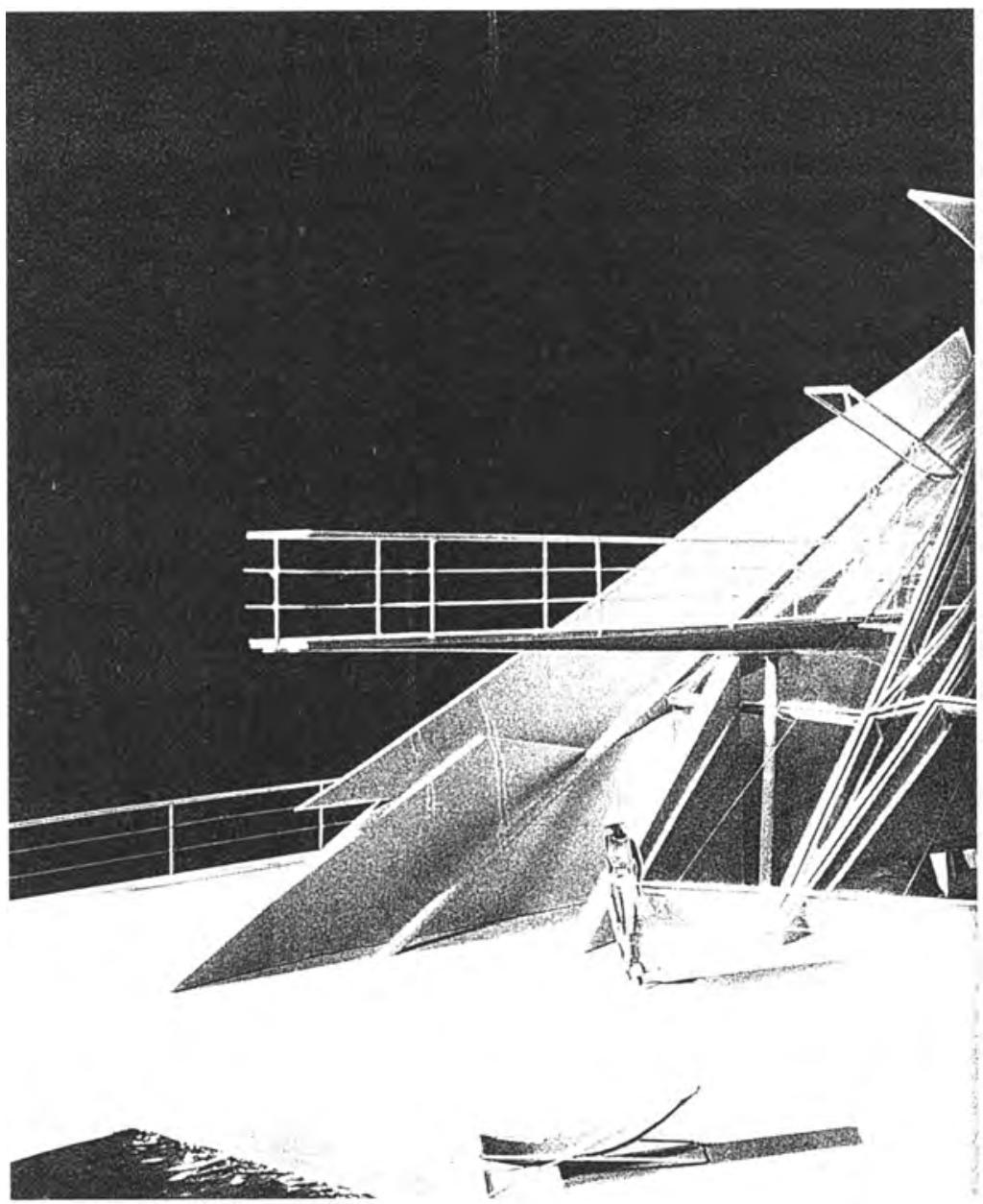

Coop Himmelblau Open House, Malibu (1992). 